\title{
Yield Stress of CCSS Thin Rectangular Plate in Postbuckling Load Regimes
}

\author{
Oguaghamba O. A. ${ }^{1}$, Ibearugbulem M. O. ${ }^{2}$, Mbachu V. C. ${ }^{3}$ \\ ${ }^{1}$ Civil Engineering Department, Imo State University, Owerri, Imo State, Nigeria \\ ${ }^{2}$ Civil Engineering Department, Federal University of Technology, Owerri, Imo State, Nigeria \\ ${ }^{3}$ Civil Engineering Department, University of Nigeria, Nsukka, Enugu State, Nigeria
}

\begin{abstract}
The objective of this study is to analyse the buckling and postbuckling yield stressof CCSSthin rectangular plate. Here, the exact displacement and stress profiles of the plate were obtained by applying the direct integration theory to the Kirchhoff's linear governing differential equation and von Karman's non-linear governing differential compatibility equation respectively. With these, the buckling and postbuckling load expression of the CCSS plate was obtained by applying work principle to the Von Karman's non-linear governing differential equilibrium equation. CCSS thin rectangular plate strength was obtained in terms of its yield/maximum stress. Other related parameters of the plate such as: displacement parameter, Wuv, stress coefficient, Wuv ${ }^{2}$ and load factor, $K_{c x}$ were determined. Results of this study show that for a CCSS plate material having yield stress of $250 \mathrm{MPa}$ at unit aspect ratio, failure would occur only at $1.8 \mathrm{~h}$ postbuckling out of plane deflection (i.e., extra tolerable load of , 103.63MPa), contrary to the presumed critical buckling load of $148.207 \mathrm{Mpa}$. The inplane load develops bending stress of $77.143 \mathrm{MPa}$, while the direct buckling and postbuckling load accountsfor174.7MPa, prior to failure. These stresses cumulate to the yield stress of the plate. Hence, CCSS plate would tolerate additional load on deflection, prior to its material and structural failure. It possessespostbuckling strength in addition to its critical buckling strength.
\end{abstract}

Keywords: Buckling, Coupled Equations, Direct Integration, Postbuckling, Work Principle, Yield stress

\section{Introduction}

A plate is a flat thin sheet of material bounded by most times, two parallel planes (faces), and a cylindrical or flat surface, called an edge or boundary. Thin plates are plates whose width to thickness ratio ranges between $8-100$. They may be referred to thin plates under small to thin plates under large deflections when their maximum deflection, $w_{\max }$ falls between $0.2 h$ to $5 h$; where $\mathrm{h}$ is the plate's thickness. Thin plates transit from their stable state of equilibrium to the unstable one, under inplane compression. Such transition is normally referred to as buckling or structural instability. In this behaviour under inplane compression, a critical point exists where an infinitesimal increase in load can cause the plate surface to buckle. The load at this critical point defines the buckling strength of the plate, or the critical or buckling load. Increases in load beyond the load at the initiation of buckling increase the buckling deformations until collapse occurs. Thus, the load at collapse defines the postbuckling or crippling strength of the plate.

Thin rectangular plate has four edges. The edges may be free, clamped, simply supported or mixed. Capital letters C, $\mathrm{F}$, and $\mathrm{S}$ are commonly used to abbreviate or designate clamped edge, free edge, and simply supported edge respectively. The labelling and naming of CCSS plate in relation to the edge conditions, e along their strips are explained in Fig 1.
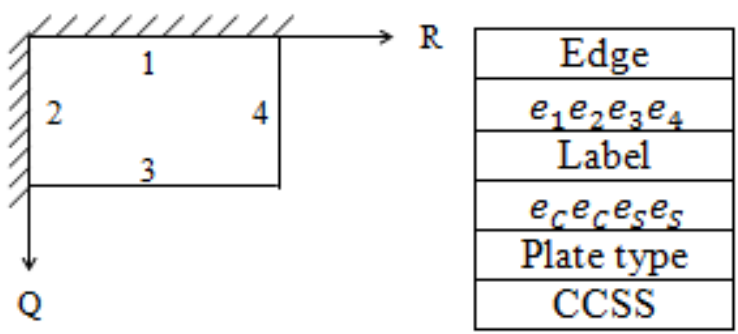

Figure 1: Procedure for naming plate with different edge conditions

Postbuckling of plates may readily be understood through an analogy to a simple grillage model, as shown in Fig.2. In the grillage model, the continuous plate is replaced by vertical columns and horizontal ties. Under loading on the $\mathrm{x}$ - edges, the vertical columns will buckle. If they were not connected to the ties, they would buckle at the same load and no postbuckling reserve would exist. However, the ties are stretched as the columns buckle outward, thus restraining the motion and providing postbuckling reserve. The columns nearer to the supported edge are restrained more by the ties than those in the middle. This occurs too in a real plate, as more of the longitudinal in-plane compression is carried nearer the edges of the plate than in the centre. Thus, the grillage model provides a working analogy for both the source of the postbuckling reserve and its most important result; i.e., re-distribution of longitudinal stresses. 


\section{International Journal of Science and Research (IJSR) ISSN (Online): 2319-7064}

Index Copernicus Value (2013): 6.14 | Impact Factor (2014): 5.611

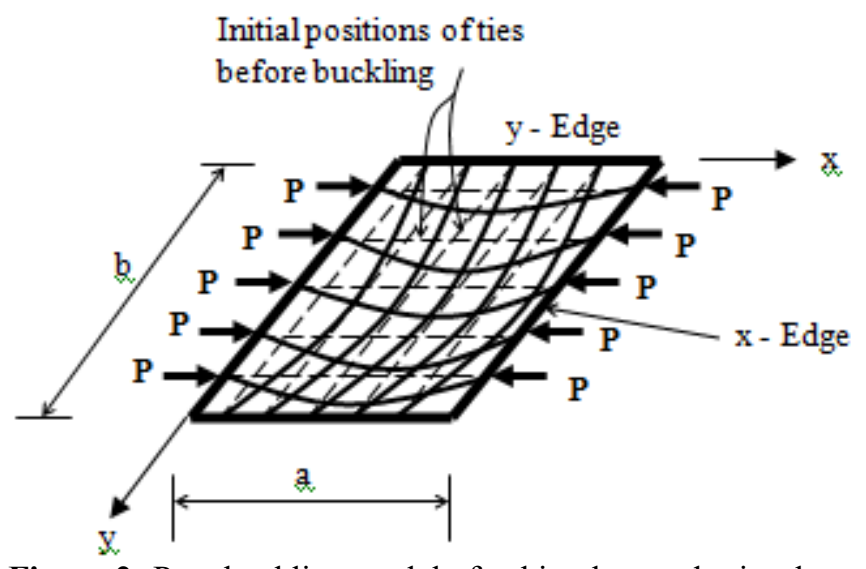

Figure 2: Post-buckling model of a thin plate under in-plane load, $\mathrm{p}$

In his context, Chaje [1] defined postbuckling load as the increase in stiffness with increase in deflection characteristic of the plate. This represents possible resistance of axial load by plate at excess of the critical load subsequent to buckling. Hence, the postbuckling response of thin elastic plates is very important in engineering analysis. Therefore, concerted effort to thoroughly studying thin plates postbuckling behaviour becomes imminent.

Postbuckling load analysis of thin plates accounts for the membrane stretching and their corresponding strains and stresses, while buckling analysis accounts also for the membrane stretching but do not consider the corresponding strains and stresses developed by the stretching. Postbuckling load analysis of plate involves nonlinear largedeflection plate bending theory, contrary to buckling load study which is based on classical or Kirchhoff's linear theory of plates. Researchers have not done much on postbuckling behaviour of thin plates as its analysis involves nonlinear large-deflection plate theory, which usually reduces to two indeterminate nonlinear governing differential equations originally derived by Von Karman in $1910[2,3]$. These equations are written as follows:

$$
\begin{aligned}
& \frac{\partial^{4} \phi}{\partial \mathrm{x}^{4}}+ 2 \frac{\partial^{4} \phi}{\partial \mathrm{x}^{2} \partial \mathrm{y}^{2}}+\frac{\partial^{4} \phi}{\partial \mathrm{y}^{4}}=\mathrm{E}\left[\left(\frac{\partial^{2} \mathrm{w}}{\partial \mathrm{x} \partial \mathrm{y}}\right)^{2}-\frac{\partial^{2} \mathrm{w}}{\partial \mathrm{x}^{2}} \frac{\partial^{2} \mathrm{w}}{\partial \mathrm{y}^{2}}\right] \\
& \frac{\partial^{4} \mathrm{w}}{\partial \mathrm{x}^{4}}+2 \frac{\partial^{4} \mathrm{w}}{\partial \mathrm{x}^{2} \partial \mathrm{y}^{2}}+\frac{\partial^{4} \mathrm{w}}{\partial \mathrm{y}^{4}} \\
&=\frac{h}{D}\left[\frac{\partial^{2} \phi}{\partial y^{2}} \frac{\partial^{2} w}{\partial x^{2}}+\frac{\partial^{2} \phi}{\partial x^{2}} \frac{\partial^{2} w}{\partial y^{2}}-2 \frac{\partial^{2} \phi}{\partial x \partial y} \frac{\partial^{2} w}{\partial x \partial y}\right] \\
&=N_{x} \frac{\partial^{2} w}{\partial x^{2}}+2 N_{x y} \frac{\partial^{2} w}{d x d y}+N_{y} \frac{\partial^{2} w}{\partial y^{2}}
\end{aligned}
$$

Where, $\phi$ is the stress function, $\mathrm{w}$ is deflection function, $\mathrm{h}$ is the plate's thickness and D is flexural rigidity. Equation 1 is the -Compatibility Equation". It ensures that in an elastic plate the in-plane and out-of-plane displacements are compatible. Equations 2 and 3 are based on equilibrium principles of stress and in-plane loads respectively. They are termed Equilibrium equations" [2, 3]. Equations 1 and 2 are usually called Von Karman's coupled equations.
The exact solutions of these equations have been a rigor from the conceptual time to the recent time, in which the coupled solutions would give the buckling/postbuckling load of plates from which the true failure load is determined. This exact solutions of these equation is imminent, as the critical load predicted by buckling analysis is adjudged unsatisfactory $[1,4]$.

Despite these revelations, very few researchers have made effort to solving these coupled equations to obtain the expressions for the buckling/postbuckling load as well as the actual failure load of thin rectangular plates under compression. Researchers such as: Von Karman et. al.[5], Marguerre [6], Levy [7], Timoshenko and Woinowsky Krieger [8], Volmir [9], Iyengar [10], Ventsel and Krauthammer [11], Chai [12]; and Yoo and Lee [13]have tried to solve these equations to obtain the buckling/postbuckling load as well as the actual failure load of thin rectangular plates under uniaxial compression. They tried to solve the problem by assuming double trigonometric solutions for deflection, $\mathrm{w}$ and stress, $\phi$ functions to solve the governing differential equations of thin rectangular plates. In which case, the buckling/postbuckling load as well as the actual failure load of thin rectangular plates under compression they obtained would also be said to be assumed, as the solutions of the governing differential equations of the plate (deflection and stress functions) were assumed abinitio. No researcher has bothered to solve for these parameters by the direct solution of these coupled governing differential equations.

In addition, these researchers restricted themselves to the use of either direct variational or indirect variational energy methods to finally evaluate the buckling/postbuckling load of this simply supported edges thin rectangular plate. None of the researchers considered applying direct work principle to finally evaluate the buckling/postbuckling loads of the CCSS plate or any other plate.

Von Karman evaluated the final buckling/postbuckling loads characteristics of SSSS plate by solving the equilibrium equation 3, after assuming trigonometric functions for deflection and stressVon Karman et. al.[5]. Marguerre [6], Timoshenko and Woinowsky - Krieger [8] and Volmir [9] also assumed doubled trigonometric functions of deflection and stress; and employed the principle of minimum potential energy, rather than the equilibrium equation to furnish the final solution for the same SSSS plate. Iyengar [10], Ventsel and Krauthammer [11], Chai [12] and Yoo and Lee[13]also assumed doubled trigonometric functions of deflection and stress used Galerkin's energy methods to obtain the final buckling/postbuckling load of SSSS plate.

Researchers in later years very often assumed doubled trigonometric functions of deflection and stress and used a similar type of approach, i.e., combining an exact solution of the compatibility equation with either evaluation and minimization of the potential energy, or an approximate solution (for example, using Galerkin's method, Ritz method or Rayleigh-Ritz method) of the equilibrium equation.

In all these, none of these researchers obtained the displacement parameter, $\mathrm{W}_{\mathrm{uv}}$, stress coefficient, $\mathrm{W}_{\mathrm{uv}}{ }^{2}$ and 


\section{International Journal of Science and Research (IJSR) \\ ISSN (Online): 2319-7064 \\ Index Copernicus Value (2013): 6.14 | Impact Factor (2014): 5.611}

load factor, $\mathrm{K}_{\mathrm{cx}}$ associated with the SSSS plate buckling and postbuckling characteristics, or any other plate. This situation has been the bane of comprehensive solution of the buckling/postbuckling characteristics of plates, as the actual yield/maximum stress of the plate could not be obtained, which this paper addressed.

\section{The Direct Integration Approach for Exact General Deflection and Stress Profile for Buckling and Postbuckling of CCSS Plate}

Oguaghamba[14] used direct integral calculus approach and evaluated equation 3 to obtain the exact general displacement function of a buckled plate. The deflection function, $\mathrm{W}$ in its non - dimensional coordinates: $\mathrm{R}$ and $\mathrm{Q}$ is given as:

$$
\mathrm{W}(\mathrm{R}, \mathrm{Q})=\Lambda \sum_{\mathrm{m}=0}^{4} \sum_{\mathrm{n}=0}^{4} \mathrm{U}_{\mathrm{m}} \mathrm{R}^{\mathrm{m}} \mathrm{V}_{\mathrm{n}} \mathrm{Q}^{\mathrm{n}}
$$

Where non - dimensional coordinates: $\mathrm{R}$ and $\mathrm{Q}$ in equation 4 relates to the usual independent coordinates $\mathrm{x}$ and $\mathrm{y}$ by the relation:

$$
\mathrm{x}=\mathrm{aR}: 0 \leq R \leq 1 \text { and } \mathrm{y}=\mathrm{bQ}: 0 \leq Q \leq 1
$$

$\mathbf{U}_{\mathbf{m}}$ and $\mathbf{V}_{\mathbf{n}}$ arecoefficients to be determined.

Solving equation 1 by direct integral calculus approach, the stress distribution of the plate at buckling and postbuckling load regimes is obtained[14]. This expression in nondimensional coordinates, $\mathrm{R}$ and $\mathrm{Q}$ is given as:

$$
\begin{aligned}
& \phi(R, Q)=\frac{E p^{2} \Lambda^{2}}{\left(1+2 p^{2}+\mathrm{p}^{4}\right)}\left[\left[\left(\frac{U_{1}^{2}}{24} R^{4}+\frac{U_{1} U_{2}}{30} R^{5}+\right.\right.\right. \\
& \frac{1}{180}\left(2 U_{2}{ }^{2}+3 U_{1} U_{3}\right) R^{6}+\frac{1}{210}\left(2 U_{1} U_{4}+3 U_{2} U_{3}\right) R^{7}+ \\
& \left.\frac{1}{1680}\left(16 U_{2} U_{4}+9 U_{3}{ }^{2}\right) R^{8}+\frac{U_{3} U_{4}}{126} R^{9}+\frac{U_{4}{ }^{2}}{315} R^{10}\right) \times \\
& \left(\frac{V_{1}^{2}}{24} Q^{4}+\frac{V_{1} V_{2}}{30} Q^{5}+\frac{1}{180}\left(2 V_{2}^{2}+3 V_{1} V_{3}\right) Q^{6}+\right. \\
& \frac{1}{210}\left(2 V_{1} V_{4}+3 V_{2} V_{3} Q^{3}\right) Q^{7}+\frac{1}{1680}\left(16 V_{2} V_{4}+\right. \\
& \left.\left.9 V_{3}{ }^{2}\right) Q^{8}+\frac{V_{3} V_{4}}{126} Q^{9}+\frac{V_{4}{ }^{2}}{315} Q^{10}\right)-\left(\frac{U_{0} U_{2}}{12} R^{4}+\right. \\
& \frac{1}{60}\left(3 U_{0} U_{3}+U_{1} U_{2}\right) R^{5}+\frac{1}{180}\left(6 U_{0} U_{4}+3 U_{1} U_{3}+\right. \\
& \left.U_{2}{ }^{2} R^{6}\right)+\frac{1}{210}\left(3 U_{1} U_{4}+2 U_{2} U_{3}\right) R^{7}+\frac{1}{210}\left(3 U_{1} U_{4}+\right. \\
& \left.2 U_{2} U_{3}\right) R^{7}+\frac{1}{840}\left(3 U_{3}^{2}+7 U_{2} U_{4}\right) R^{8}+\frac{U_{3} U_{4}}{168} R^{9}+ \\
& \left.\frac{U_{4}{ }^{2}}{420} R^{10}\right) \times\left(\frac{V_{0} V_{2}}{12} Q^{4}+\frac{1}{60}\left(3 V_{0} V_{3}+V_{1} V_{2}\right) Q^{5}+\right. \\
& \frac{1}{180}\left(6 V_{0} V_{4}+3 V_{1} V_{3}+V_{2}^{2}\right) Q^{6}+\frac{1}{210}\left(3 V_{1} V_{4}+\right. \\
& \left.2 V_{2} V_{3}\right) Q^{7}+\frac{1}{840}\left(3 V_{3}{ }^{2}+7 V_{2} V_{4}\right) Q^{8}+\frac{V_{3} V_{4}}{168} Q^{9} \\
& \left.\left.+\frac{V_{4}^{2}}{420} Q^{10}\right)\right]-\frac{N_{c x} b^{2}}{2 h} Q^{2}
\end{aligned}
$$

$\mathbf{U}_{\mathbf{m}}$ and $\mathbf{V}_{\mathbf{n}}$ coefficients in equations 4 and 6 were determined by Oguaghamba[14] using the Benthem's boundary conditions of CCSS plate as follows:

$\mathrm{U}_{\mathrm{o}}=0 ; \mathrm{U}_{1}=\mathrm{U}_{4} ; \mathrm{U}_{2}=0 ; \mathrm{U}_{3}=-2 \mathrm{U}_{4} ; \mathrm{U}_{4}=\mathrm{U}_{4} ;$

$$
\mathrm{V}_{\mathrm{o}}=0 ; \mathrm{V}_{1}=0 ; \mathrm{V}_{2}=\mathrm{V}_{4} ; \mathrm{V}_{3}=-2 \mathrm{~V}_{4} ; \mathrm{V}_{4}=\mathrm{V}_{4}
$$

Hence, the CCSS plate displacement and stress profiles in buckling and postbuckling regimes are obtained by substituting these coefficients into equations 4 and 6 . The substitution gives:

$$
\begin{gathered}
W(R, Q)=W_{u v} h_{1}(R, Q) \\
\phi(R, Q)=\varphi W_{u v}^{2} h_{2}(R, Q)-\frac{N_{c x} b^{2}}{2 h} Q^{2}
\end{gathered}
$$

$\mathrm{W}_{\mathrm{uv}}^{2}=$ Stress function coefficient for a plate in postbuckling regime

where,

$W_{u v}=\Lambda U_{4} V_{4}$

$\Lambda=$ Consolidated coefficient factor of deflection in buckling regime

$$
\begin{gathered}
\mathrm{h}_{1}(R, Q)=\left(1.5 R^{2}-2.5 R^{3}+R^{4}\right)\left(1.5 Q^{2}-2.5 Q^{3}+\right. \\
\left.Q^{4}\right)
\end{gathered}
$$

$\mathrm{h}_{2}(\mathrm{R}, \mathrm{Q})=$ Non-dimensional stress shape (profile) function of the slightly bent plate, given as:

$$
\begin{gathered}
\mathrm{h}_{2}(\mathrm{R}, \mathrm{Q})=\frac{1}{406425600}\left[\left(504 R^{6}-1080 R^{7}+963 R^{8}-\right.\right. \\
\left.400 R^{9}+64 R^{10}\right)\left(504 Q^{6}-1080 Q^{7}+963 Q^{8}-400 Q^{9}\right. \\
\left.+64 Q^{10}\right)-36\left(42 R^{6}-120 R^{7}+117 R^{8}-50 R^{9}+\right. \\
\left.\left.8 R^{10}\right)\left(42 Q^{6}-120 Q^{7}+117 Q^{8}-50 Q^{9}+8 Q^{10}\right)\right]- \\
\varphi=\frac{\mathrm{Ep}^{2}}{\left(1+2 \mathrm{p}^{2}+\mathrm{p}^{4}\right)}
\end{gathered}
$$

$\mathrm{E}$ is the elastic modulus of plate and $\mathrm{p}$ is the aspect ratio.

Expressions for the deflection and stress functions factors, $W_{u v}$ and $W_{u v}^{2}$ of the plate behaviour under pre - buckling, buckling and post buckling regimes deduced by Oguaghamba [14] is given as:

$$
W_{u v}=64 \alpha \mathrm{h} ; W_{u v}^{2}=W_{u v}^{2}=4096 \alpha^{2} \mathrm{~h}^{2}
$$

\section{Work Principle Application for Buckling and Postbuckling Load and Stress of CCSS Plate}

Oguaghamba[14] applied the work principle according to Ibearugbulemet al. $[15,16]$ to equation 2 in non dimensional coefficient and obtained the exact general buckling and postbuckling load, $\mathrm{N}_{\mathrm{cx}}(\mathrm{R}, \mathrm{Q})$ of thin rectangular plates in non - dimensional coordinates as in equation 13

$$
N_{c x}=\left(-\frac{49}{484} \beta+\frac{294}{121} \frac{\left(1-\mu^{2}\right) \mathrm{p}^{2} W_{u v}^{2}}{\left(1+2 \mathrm{p}^{2}+\mathrm{p}^{4}\right) \mathrm{h}^{2}} \psi\right) \frac{\pi^{2} D}{b^{2}}
$$

where,

$$
\beta=\frac{\iint_{0,0}^{1,1}\left(\frac{\partial^{4} h_{1}}{p^{2} \partial R^{4}} \cdot h_{1}+\frac{2 \partial^{4} h_{1}}{\partial R^{2} \partial Q^{2}} \cdot h_{1}+p^{2} \frac{\partial^{4} h_{1}}{\partial Q^{4}} \cdot h_{1}\right) d R d Q}{\iint_{0,0}^{1,1}\left(\frac{\partial^{2} h_{1}}{\partial R^{2}} \cdot h_{1}\right) d R d Q}
$$

$\psi=$

$$
\frac{\iint_{0,0}^{1,1}\left(\frac{\partial^{2} \mathrm{~h}_{1}}{\partial \mathrm{Q}^{2}} \frac{\partial^{2} \mathrm{~h}_{2}}{\partial \mathrm{R}^{2}}+\frac{\partial^{2} \mathrm{~h}_{1}}{\partial \mathrm{R}^{2}} \cdot \frac{\partial^{2} \mathrm{~h}_{2}}{\partial \mathrm{Q}^{2}}-\frac{2 \partial^{2} \mathrm{~h}_{1}}{\partial \mathrm{R} \partial \mathrm{Q}} \frac{\partial^{2} \mathrm{~h}_{2}}{\partial \mathrm{R} \partial \mathrm{Q}}\right) \mathrm{h}_{1} \mathrm{dRdQ}}{\iint_{0,0}^{1,1}\left(\frac{\partial^{2} \mathrm{~h}_{1}}{\partial \mathrm{R}^{2}} \cdot \mathrm{h}_{1}\right) \mathrm{dRdQ}}
$$




\section{International Journal of Science and Research (IJSR) \\ ISSN (Online): 2319-7064}

Index Copernicus Value (2013): 6.14 | Impact Factor (2014): 5.611

where the first and the second terms account for critical buckling load of the plate and the gain in load of the plate at postbuckling regime respectively.

Substituting the expressions of $\mathrm{h}_{1}(R, Q)$ and $h_{2}(R, Q)$ into equations 14 and 14; solving out the resulting integrand expressions and substituting their results into equation 13 gave the buckling and postbuckling load expression for anCCSS thin rectangular plate as:

$$
\begin{aligned}
\mathrm{N}_{\mathrm{cx}}= & {\left[\left(\frac{2.12603306}{P^{2}}+2.30187038+2.12603306 P^{2}\right)\right.} \\
& \left.+3.86970915 \times 10^{-4} \frac{\left(1-\mu^{2}\right) \mathrm{p}^{2} W_{u v}^{2}}{\left(1+2 \mathrm{p}^{2}+\mathrm{p}^{4}\right) \mathrm{h}^{2}}\right] \frac{D \pi^{2}}{b^{2}}
\end{aligned}
$$

Introducing the expression of $W_{u v}^{2}$ given in equation 12 into equation 16; the buckling and postbuckling load expression for anCCSS thin rectangular plate reduced to:

$$
\begin{array}{r}
N_{c x}=\left(\frac{2.12603306}{P^{2}}+2.30187038+2.12603306 P^{2}\right) \\
\left.+1.5891288694 \frac{\mathrm{p}^{2} \alpha^{2}\left(1-\mu^{2}\right)}{\left(1+2 \mathrm{p}^{2}+\mathrm{p}^{4}\right)}\right] \frac{\mathrm{D} \pi^{2}}{\mathrm{~b}^{2}} \\
\mathrm{~N}_{\mathrm{cx}}=\mathrm{K}_{\mathrm{cx}} \frac{\mathrm{D}^{2}}{\mathrm{~b}^{2}} \\
+1.5891288694 \frac{\mathrm{p}^{2} \alpha^{2}\left(1-\mu^{2}\right)}{\left(1+2 \mathrm{p}^{2}+\mathrm{p}^{4}\right)}
\end{array}
$$

where, $K_{c x}$ is the buckling and postbuckling load coefficient.

Oguaghamba [14] also obtained the general expression of theinplane and bending buckling and postbuckling yield stress developed by thin rectangular plates as:

$$
\begin{gathered}
\sigma_{x_{\text {max }}}=\frac{N_{c x}}{h}-\frac{6 \mathrm{D}}{\mathrm{h}^{2} b^{2}} \Lambda\left(\frac{1}{\mathrm{P}^{2}}\left(2 \mathrm{U}_{2}+6 \mathrm{U}_{3} \mathrm{R}+12 \mathrm{U}_{4} \mathrm{R}^{2}\right) \times\right. \\
\left(\mathrm{V}_{\mathrm{o}}+\mathrm{V}_{1} \mathrm{Q}+\mathrm{V}_{2} \mathrm{Q}^{2}+\mathrm{V}_{3} \mathrm{Q}^{3}+\mathrm{V}_{4} \mathrm{Q}^{4}\right)+\mu\left(\mathrm{U}_{\mathrm{o}}+\mathrm{U}_{1} \mathrm{R}+\right. \\
\left.\left.\mathrm{U}_{2} \mathrm{R}^{2}+\mathrm{U}_{3} \mathrm{R}^{3}+\mathrm{U}_{4} \mathrm{R}^{4}\right)\left(2 \mathrm{~V}_{2}+6 \mathrm{~V}_{3} \mathrm{Q}+12 \mathrm{~V}_{4} \mathrm{Q}^{2}\right)\right)(20)
\end{gathered}
$$

Introducing $\mathbf{U}_{\mathbf{m}}$ and $\mathbf{V}_{\mathbf{n}}$ coefficients as determined by Oguaghamba [14] for CCSS plate and the $\boldsymbol{N}_{\boldsymbol{c} x}$ expression in equation (17),we obtain the inplane and bending buckling and postbuckling yield stress developed by the CCSS:

$\sigma_{c r i}=\frac{N_{c x}}{h}+1.125 \frac{\mathrm{D}}{\mathrm{h}^{2}} \frac{\alpha}{\mathrm{h}_{1 \max }}\left(\frac{1}{\mathrm{P}^{2}}+\mu\right)(21)$

Where $\mathrm{h}_{1 \text { max }}$ is the non - coefficient displacement at critical yield of the plate. The value is $1 / 64$ for CCSS plate [14].

Hence, equation 12 becomes:

$\sigma_{c r i}=\left[\left(\frac{2.12603306}{P^{2}}+2.30187038+2.12603306 P^{2}\right)\right.$

$\left.+1.5891288694 \frac{\mathrm{p}^{2} \alpha^{2}\left(1-\mu^{2}\right)}{\left(1+2 \mathrm{p}^{2}+\mathrm{p}^{4}\right)}\right] \frac{\boldsymbol{D} \boldsymbol{\pi}^{2}}{h \boldsymbol{b}^{2}}+$

$72 \frac{\mathrm{D}}{\mathrm{h} b^{2}} \alpha\left(\frac{1}{\mathrm{P}^{2}}+\mu\right)$

\section{Results and Discussions}

Fig. 2 shows a CCSS thin rectangular plate subjected to uniaxial compression loads on the $\mathrm{R}$ - edges. The interest is to evaluate the buckling and postbuckling load of the plate.

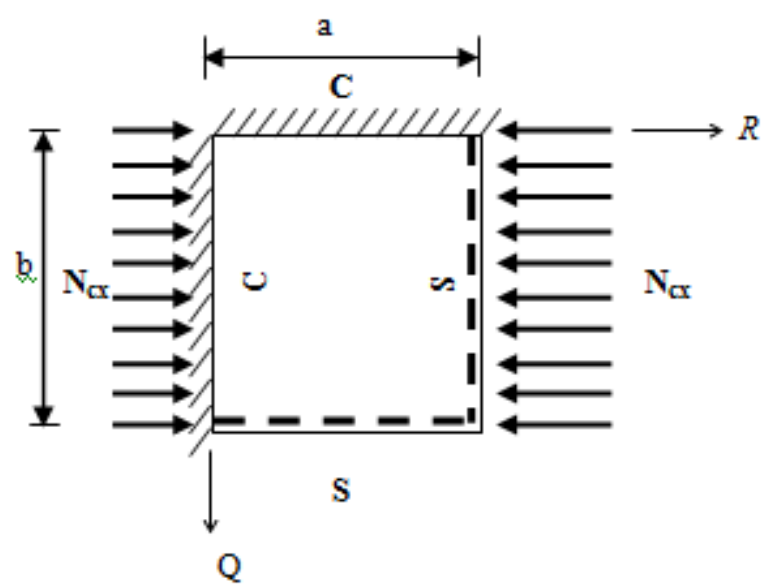

Figure 2: CCSS - Thin Rectangular Plate under Uniaxial Load

Iyengar [10]; Ventsel and Krauthammer [11]; Szilard [4] and Yoo and Lee [13] in their separate works obtained only the buckling and postbuckling load of SSSS - thin rectangular plate as:

$\mathbf{N}_{\mathrm{cx}}=\left[\left(\frac{1}{\mathbf{P}^{2}}+2+\mathbf{P}^{2}\right)+3\left(\frac{1}{\mathbf{p}^{2}}+\mathbf{p}^{2}\right) \frac{\mathbf{W}_{11}^{2}}{\mathbf{h}^{2}} \frac{\left(1-\mu^{2}\right)}{4}\right] \frac{\mathbf{D} \pi^{2}}{\mathbf{b}^{2}}$

No other researcher has obtained the buckling and postbuckling load of CCSS - thin rectangular plate. Even the SSSS plate as obtained by Iyengar [10]; Ventsel and Krauthammer [11]; Szilard [4]; and Yoo and Lee [13] is inconclusive, as the stress function coefficient, $\mathbf{W}_{\mathbf{1 1}}^{2}$ in their formulation wasneither defined or was attributed to any empiricalinterpretation.This leaves their formulation as a mere theoretical exercise rather than real life adventure.

The present study clearly defined these parameters: the displacement parameter, $\mathbf{W}_{\mathbf{u v}}$, stress coefficient, $\mathbf{W}_{\mathbf{u v}}{ }^{2}$ and load factor, $\mathbf{K}_{\mathbf{c x}}$. With this parameters, the present study obtained critical yield stress of the CCSS plate under buckling and postbuckling loads as given in equation 22 . Therefore, equations 17 and 22 can be used to obtain the actual value of the buckling and postbuckling load and critical yield stress of an CCSS plate, knowing other parameters: deflection coefficient, $\boldsymbol{\alpha}$; Poisson ration, $\mu$; breadth, $b$; aspect ratio, $p$ and thickness, $h$ of the plate.

For instance, an ASTM grade A36 thin rectangular steel plate possessing CCSS edge conditions; subjected to uniformly distributed in-plane load on its $\mathrm{R}$ - edge, $\mathrm{b}$ and having the following physical and geometric properties as: breadth, $\mathrm{b}=4000 \mathrm{~mm}$; thickness of plate, $\mathrm{h}=20 \mathrm{~mm}$; yield load, $\sigma_{\mathrm{ys}}=250 \mathrm{MPa}$; Ultimate Stress, $\sigma_{\mathrm{u}}=400-550 \mathrm{MPa}$; Poisson's ratio, $\mu=0.30$; Modulus of elasticity, $\mathrm{E}=200$ GPa; density of plate, $\rho=7,800 \mathrm{~kg} / \mathrm{m}^{3}$. The buckling and postbuckling load coefficient and critical yield stress of the plate through unit aspect ratio and deflection coefficients range: $0 \leq \alpha \leq 5.0$ are shown in Fig. 3 and Fig. 4 respectively. 


\section{International Journal of Science and Research (IJSR) ISSN (Online): 2319-7064 \\ Index Copernicus Value (2013): 6.14 | Impact Factor (2014): 5.611}

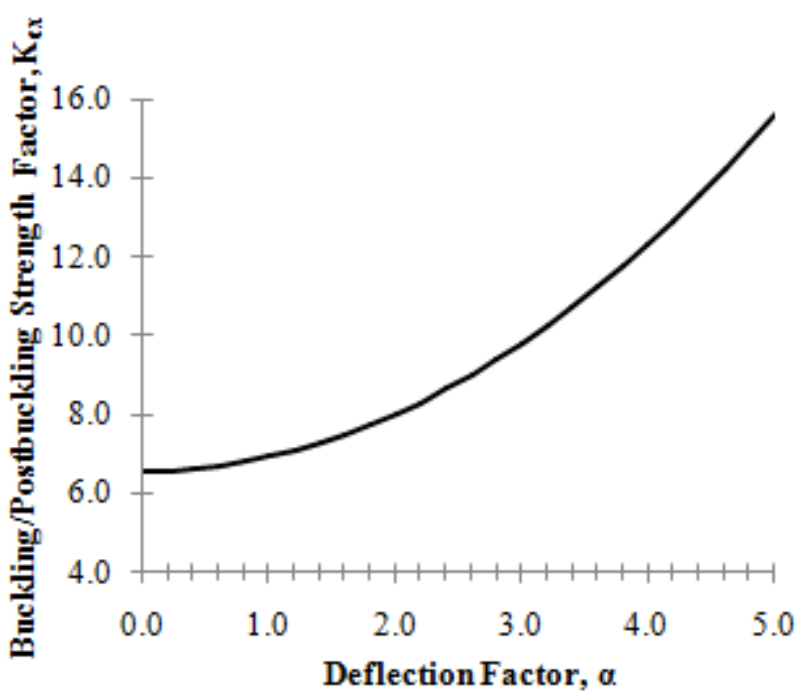

Figure 3: Buckling and Postbuckling Load Coefficient, $K_{c x}$ and Deflection Factor, $\alpha$ at aspect ratio of unity for CCSS Plate

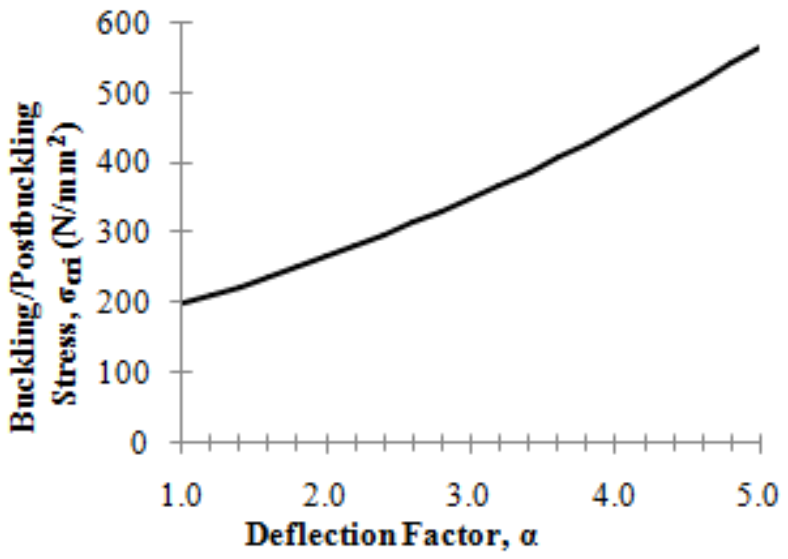

Figure 4: Buckling and postbuckling load critical yield/maximum stress, $\sigma_{\text {cri }}$ and deflection Factor, $\alpha$ at aspect ratio of unity for CCSS - Plate

Fig. 3 shows that the buckling and postbuckling load parameter, $\mathrm{K}_{\mathrm{cx}}$ increases quadratically as the out of plane deflection factor, $\alpha$ increases. The behaviour of buckling and postbuckling load parameter is a function of the buckling and postbuckling load. It means that the buckling and postbuckling load would continue to increase as the out of plane deflection increases. This is contrary to the literature's hypothesis that the axial stiffness reduces, as the plate as a whole sustains increase in load after buckling or deflection [14].

However, this hypothesis is further clarified in Fig. 4. The linear relationship in the yield stress behaviour against out of plane deflection explained that the plate would resist extra in-plane load after buckling, while reduces in its material stiffness. That is, the plate resists further in-plane load due to postbuckling reserve but loses stiffness due to in-plane bending stress developed. Fig. 4 also show that for a CCSS plate material having yield stress of $250 \mathrm{MPa}$, failure of such plate under in-plane loading would not occur until the out of plane deflection of the plate is about (1.8h). It is at this point that the induced stress in the plate would reach the failure stress for the plate material, which may cause failure of the plate. The buckling and postbuckling stresses, $\sigma_{c r i}$ are even higher at other aspect ratios lower than 1.0, as shown in Tabe 1. CCSS plate possesses such increased load resistance because the edges which are simply supports and clamped allow stretching of the longitudinal fibers of the plate on deformation. In this way, the longitudinal fibers of the plate would undergo stress redistribution under load, as well as develop transverse tensile stresses after buckling. These tensile stresses provide the postbuckling reserve load. Thus, additional load may often be applied to somegeometric deformation without reaching material yield stress or imposing structural damage to the plate.

However, as the structural requirements for plates are that the structure should not be so flexible that the behaviour causes alarm or discomfort to the users; other structural criteria may be applied to select the applicable load below this yield stress, which is also far above the buckling load.

For instance, at zero deformation (critical buckling load), the yield stress of the plate for aspect ratio of unity is 148.207MPa. This is below the design yield stress of the plate. Extra $103.631 \mathrm{MPa}$ on $1.8 \mathrm{~h}$ deformation can be tolerated by the plate prior to material and structural. This happens at postbuckling regime.

Table 1: CCSS Plate Buckling and Postbuckling Strength,

\begin{tabular}{|c|c|c|c|c|}
\hline \multirow{3}{*}{$\mathrm{P}$} & \multicolumn{4}{|c|}{$0.00 \leq \alpha \leq 0.60$} \\
\hline & $\mathbf{0}$ & 0.20 & 0.40 & 0.60 \\
\hline & \multicolumn{4}{|c|}{$\sigma_{c r i}-$ Values $(\mathrm{MPa})$} \\
\hline 0.5 & 256.380 & 284.941 & 313.921 & 343.319 \\
\hline 0.6 & 202.908 & 223.456 & 244.512 & 266.078 \\
\hline 0.7 & 173.727 & 189.450 & 205.750 & 222.627 \\
\hline 0.8 & 157.943 & 170.534 & 183.748 & 197.585 \\
\hline 0.9 & 150.350 & 160.791 & 171.879 & 183.615 \\
\hline 1.0 & 148.207 & 157.105 & 166.658 & 176.864 \\
\hline \multirow{3}{*}{$\mathrm{P}$} & \multicolumn{4}{|c|}{$0.80 \leq \alpha \leq 1.40$} \\
\hline & 0.80 & 1.00 & 1.20 & 1.40 \\
\hline & \multicolumn{4}{|c|}{$\sigma_{c r i}-$ Values $(\mathrm{MPa})$} \\
\hline 0.5 & 373.135 & 403.371 & 434.024 & 465.097 \\
\hline 0.6 & 288.154 & 310.738 & 333.832 & 357.434 \\
\hline 0.7 & 240.082 & 258.114 & 276.724 & 295.911 \\
\hline 0.8 & 212.044 & 227.125 & 242.829 & 259.156 \\
\hline 0.9 & 195.996 & 209.025 & 222.701 & 237.023 \\
\hline 1.0 & 187.725 & 199.240 & 211.408 & 224.231 \\
\hline \multirow{3}{*}{$\mathrm{P}$} & \multicolumn{4}{|c|}{$1.60 \leq \alpha \leq 2.20$} \\
\hline & 1.60 & 1.80 & 2.00 & 2.20 \\
\hline & \multicolumn{4}{|c|}{$\sigma_{c r i}-$ Values $(M P a)$} \\
\hline 0.5 & 496.588 & 528.497 & 560.826 & 593.572 \\
\hline 0.6 & 381.546 & 406.168 & 431.298 & 456.937 \\
\hline 0.7 & 315.676 & 336.018 & 356.937 & 378.434 \\
\hline 0.8 & 276.105 & 293.676 & 311.871 & 330.687 \\
\hline 0.9 & 251.992 & 267.608 & 283.871 & 300.781 \\
\hline 1.0 & 237.707 & 251.838 & 266.623 & 282.062 \\
\hline \multirow{3}{*}{$\mathrm{P}$} & \multicolumn{4}{|c|}{$2.40 \leq \alpha \leq 3.00$} \\
\hline & 2.40 & 2.60 & 2.80 & 3.00 \\
\hline & \multicolumn{4}{|c|}{$\sigma_{c r i}-$ Values $(\mathrm{MPa})$} \\
\hline 0.5 & 626.738 & 660.321 & 694.324 & 728.745 \\
\hline 0.6 & 483.086 & 509.744 & 536.911 & 564.588 \\
\hline 0.7 & 400.508 & 423.159 & 446.388 & 470.194 \\
\hline 0.8 & 350.126 & 370.188 & 390.872 & 412.179 \\
\hline 0.9 & 318.337 & 336.541 & 355.391 & 374.888 \\
\hline 1.0 & 298.154 & 314.901 & 332.302 & 350.357 \\
\hline \multirow{2}{*}{$\mathrm{P}$} & \multicolumn{4}{|c|}{$3.20 \leq \alpha \leq 3.80$} \\
\hline & 3.20 & 3.40 & 3.60 & 3.80 \\
\hline
\end{tabular}

\section{Volume 4 Issue 11, November 2015}




\section{International Journal of Science and Research (IJSR) ISSN (Online): 2319-7064}

Index Copernicus Value (2013): 6.14 | Impact Factor (2014): 5.611

\begin{tabular}{|l|r|r|r|r|}
\hline & \multicolumn{4}{|c|}{$\sigma_{\text {cri }}-$ Values $(\boldsymbol{M P a})$} \\
\hline 0.5 & 763.585 & 798.843 & 834.520 & 870.615 \\
\hline 0.6 & 592.773 & 621.468 & 650.672 & 680.385 \\
\hline 0.7 & 494.578 & 519.539 & 545.078 & 571.194 \\
\hline 0.8 & 434.108 & 456.660 & 479.834 & 503.631 \\
\hline 0.9 & 395.031 & 415.822 & 437.260 & 459.344 \\
\hline 1.0 & 369.066 & 388.429 & 408.446 & 429.116 \\
\hline
\end{tabular}

\begin{tabular}{|c|c|c|c|c|c|}
\hline \multirow{3}{*}{$\mathrm{P}$} & \multicolumn{5}{|c|}{$4.00 \leq \alpha \leq 4.60$} \\
\hline & 4.00 & & 20 & & 4.60 \\
\hline & \multicolumn{5}{|c|}{$\sigma_{c r i}-$ Values $($ MPa $)$} \\
\hline 0.5 & 907.129 & & 4.061 & 981.412 & 1019.182 \\
\hline 0.6 & 710.607 & & 1.339 & 772.579 & 804.329 \\
\hline 0.7 & 597.887 & & 5.158 & 653.006 & 681.432 \\
\hline 0.8 & 528.050 & & 3.092 & 578.756 & 605.043 \\
\hline 0.9 & 482.075 & & 5.453 & 529.477 & 554.149 \\
\hline 1.0 & 450.441 & & 2.421 & 495.054 & 518.341 \\
\hline \multirow{3}{*}{$\mathbf{P}$} & \multicolumn{3}{|c|}{$0.00 \leq \alpha \leq 0.60$} & & \\
\hline & \multicolumn{2}{|c|}{\begin{tabular}{l|l}
4.80 \\
\end{tabular}} & 5.00 & & \\
\hline & \multicolumn{3}{|c|}{$\sigma_{c r i}-\operatorname{Values}(\mathrm{MPa})$} & & \\
\hline 0.5 & \multicolumn{2}{|c|}{1057.370} & 1095.977 & & \\
\hline 0.6 & \multicolumn{2}{|c|}{836.588} & 869.357 & & \\
\hline 0.7 & \multicolumn{2}{|c|}{710.435} & 740.015 & & \\
\hline 0.8 & \multicolumn{2}{|c|}{631.952} & 659.484 & & \\
\hline 0.9 & \multicolumn{2}{|c|}{579.467} & 605.432 & & \\
\hline 1.0 & \multicolumn{2}{|c|}{542.282} & 566.877 & & \\
\hline
\end{tabular}

\section{Conclusion}

Whereas the previous studies did not analysed the buckling and postbuckling load characteristics of CCSS plate, this paper analysed the buckling and postbuckling load characteristics of CCSS plate. Where the double trigonometric functions have been adjudged inadequate for the analysis of thin plates' postbuckling load characteristics, this study obtained exact displacement and stress profiles of buckling and postbuckling load characteristics of CCSS plate by direct integration of the governing differential equations of the plate and implored the work principle technique to finally evaluating the buckling and postbuckling load of CCSS plate. The study also obtained the buckling and postbuckling yield stress obtained for CCSS plate and other parameters of the CCSS plate under buckling and postbuckling regimes such as: displacement parameter, $\mathrm{W}_{\mathrm{uv}}$, stress coefficient, $\mathrm{W}_{\mathrm{uv}}{ }^{2}$ and load factor, $\mathrm{K}_{\mathrm{cx}}$. With all these, the study explained stiffness loss behaviour of plate in postbuckling regime. Thus, the study found out that CCSS plate would accommodate more loads beyond the critical buckling load, prior to actual material failure in its postbuckling regime. For CCSSplate's of higher yield stress, failure would be due to geometric orpermissible deflection criteria. The study also revealed that plate deforms along the transverse direction, leading to the stretching of the longitudinal fibers of the plate, when uniaxially loaded. In this way, the longitudinal fibers of the plate would undergo stress redistribution, as well as develop transverse tensile stresses. These tensile stresses provide the postbuckling reserve load.

\section{References}

[1] A. Chaje, Principles of Structural Stability Theory, London: Prentice - Hall Inc., 1974.
[2] J. Rhodes, Buckling of Thin Plates and Members and Early Work on Rectangular Tubes," Thin-Walled Structures vol. 40, pp. 87-108, 2002.

[3] J. Rhodes, - Sme observations on the Postbuckling Behaviour of Thin-Walled Members," Thin-Walled Structures,vol. 41, pp. $207-26,2003$.

[4] R. Szilard, Theories and Application of Plates Analysis: Classical, Numerical and Engineering Methods, New Jersey: John Wiley and Sons Inc., 2004.

[5] T. Von Karman, E. E. Sechler, and L. H. Donnel, Strength of Thin Plates in Compression," Trans ASME, vol. 54, pp. $53-4,1932$.

[6] K. Marguerre, Effective Width of Plates in Compression," National Advisory Council for Aeronautics, NACA Technical Note, Washington D. C., No. 833, 1937.

[7] S. Levy, Bending of Rectangular Plates with Large Deflections," National Advisory Council for Aeronautics, NACA Technical Report, Washington D.C., No. 737, 1942.

[8] S. P. Timoshenko and S. Woinowsky - Krieger, Theory of Plates and Shells, 2nd ed., Auckland: McGraw-Hill Inc., 1959.

[9] A. S. Volmir,-ATranslation of Flexible Plates and Shells," Air Force Flight Dynamics Laboratory, Ohio: Wright-Patterson Air Force Base, Technical Report No. 66-216, 1967.

[10]N. G. Iyengar, Structural Stability of Columns and Plates, New York: Ellis Horwood Limited, 1988.

[11]E. Ventsel, and T. Krauthammer, Thin Plates and Shells: Theory, Analysis and Applications, New York: Maxwell Publishers Inc., 2001.

[12]H. Chai, Eontact Buckling and Postbuckling of Thin Rectangular Plates," Journal of the Mechanics and Physics of Solids, vol. 49, pp. 209 - 30, 2001.

[13] C. H. Yoo and S. C. Lee, Stability of Structures: Principles and Applications, Amsterdam: ButterworthHeinemann, 2011.

[14]O. A. Oguaghamba, Analysis of Buckling and Postbuckling Loads of Isotropic Thin Rectangular Plates,'Ph.D. Thesis Submitted to Postgraduate School, Federal University of Technology, Owerri, Nigeria, 2015.

[15] O. M. Ibearugbulem, L. O. Ettu, and J. C. Ezeh, —Dirct Integration and Work Principle as New Approach in Bending Analyses of Isotropic Rectangular Plates," The International Journal of Engineering and Science (IJES), vol. 2 (3), pp. 28 - 36, March 2013.

[16] O. M. Ibearugbulem, O. A. Oguaghamba, K. O. Njoku, and M. Nwaokeorie, Using Line Continuum to Explain Work Principle Method for Structural Continuum Analysis," International Journal of Innovative Research and Development, vol. 3 (9), pp. 365 - 70, September 2014. 